\title{
Double dipping in hybrid open access - chimera or reality?
}

\author{
Bernhard Mittermaier* \\ Forschungszentrum Jülich, Central Library, D-52425 Jülich, Germany \\ *Corresponding author's e-mail address: b.mittermaier@fz-juelich.de
}

Published online: 25 May 2015 (version 1)

Cite as: B. Mittermaier, ScienceOpen Research 2015 (DOI: 10.14293/S2199-1006.1.SOR-SOCSCI.AOWNTU.v1)

Reviewing status: Please note that this article is under continuous review. For the current reviewing status and the latest referee's comments please click here or scan the QR code at the end of this article.

Primary discipline: Social \& Behavioral Sciences

Keywords: Hybrid open access, Double dipping, Journals, Survey

\begin{abstract}
The pros and cons of hybrid open access are heavily disputed. A main point of discussion is whether 'double dipping' takes place, i.e. paying twice to publish and read the same article. To prove publishers' assertions that they do not double dip, a survey was conducted of 24 publishers with detailed questions about their pricing policy using concrete examples. The outcome is quite sobering: the results range from partial double dipping to full double dipping, and in no instance did a 'no double-dipping' policy mean that no double dipping takes place.
\end{abstract}

\section{INTRODUCTION}

In June 2012, the British National Working Group on Expanding Access to Published Research Findings published a report entitled 'Accessibility, sustainability, excellence: how to expand access to research publications' ${ }^{1}$ ('Finch Report'). The report describes methods of improving access to scientific literature and deems 'gold' open access to be the ideal solution. This is possible by publishing in gold open access journals or by publishing in subscription journals with the option of making specific articles freely accessible upon payment of a fee ('hybrid' open access, HOA). Shortly

A longer version of this article was first published in the German journal informationspraxis, http://dx.doi.org/ 10.11588/ip.2015.1.18274. The differences to this publication are as follows:

-German language

-Focus on the situation in Germany in the introduction, rather than UK

-Consideration of additional publishers with journals in German in the survey

-Discussion of the whole survey (two additional scenarios and three additional questions which are not considered in this publication)

${ }^{1}$ http://www.researchinfonet.org/publish/finch/ (accessed 17 January 2015). afterwards, the British government accepted the recommendations in the Finch Report and adopted them as government policy. ${ }^{2}$ Subsequently, the Research Councils UK amended its own RCUK Policy on Open Access accordingly. ${ }^{3}$ Since then, the pendulum appears to have swung more strongly towards 'green' open access. The Higher Education Funding Council of England (HEFCE) has not issued any firm guidelines on which open access mechanism is to be preferred. ${ }^{4}$ In any case, this massive support (also) for hybrid open access (HOA) has reignited the discussion on HOA, which has been going on for a quite a while - and not just in the United Kingdom.

\section{HYBRID OPEN ACCESS IN THE DEBATE}

The number of journals offering HOA far exceeds demand: most of the major publishers publish less than $2 \%$ of their articles as HOA.

The overall conclusion of this study must be that the hybrid experiment, at least in the case of the major publishers and with the current price level, has failed as a way of significantly adding to the volumes of $\mathrm{OA}$ articles, and that hybrid OA will remain a very marginal phenomenon in the scholarly publishing landscape [1].

There are several reasons why authors are very reluctant to use HOA.

- The visibility of hybrid articles on publishers' websites is often unsatisfactory; furthermore, individual articles are generally not included in link resolvers [2].

\footnotetext{
${ }^{2}$ https://www.gov.uk/government/publications/letter-to-damejanet-finch-on-the-government-response-to-the-finch-groupreport-accessibility-sustainability-excellence-how-to-expandaccess-to-research-publications (accessed 17 January 2015).

${ }^{3}$ http://www.rcuk.ac.uk/RCUK-prod/assets/documents/docu ments/RCUKOpenAccessPolicy.pdf (accessed 17 January 2015).

${ }^{4}$ http://www.hefce.ac.uk/pubs/year/2014/201407/ (accessed 17 January 2015).
} 
Potential readers could therefore think that they have no access to such articles.

- For gold open access articles, a citation advantage is generally observed; freely accessible articles tend to be cited more often than closed access articles [3]. For HOA articles, in contrast, no significant increase in the number of citations has been ascertained [4].

- The fee for hybrid publications is around US\$3,000 in many cases; sometimes it is lower, but sometimes it is even higher [5]. This is considerably higher than the article publication charges (APCs) for pure OA journals, which is around US $\$ 1,000$ on average [6]. Such a situation is difficult to understand and is considered in more detail in the Discussion section.

- Despite the high fees, in many cases, publishers still retain rights to the articles, which go far beyond the 'right to publish' as such. The notion that rights to an article remain with the author and not with the publisher is apparently alien to Informa Healthcare, for example: 'Open Access is an arrangement where the copyright for an article transfers from Informa Healthcare to the public domain. This means that readers can freely access the article on our site and on any site that includes the article content. ${ }^{5}$ The publisher's HOA articles are watermarked with the comment: 'Copyright Informa Healthcare 2014. Not for Sale or Commercial Distribution. Unauthorized use prohibited. Authorized users can download, display, view and print a single copy for personal use. ${ }^{6}$

- In his SPARC Open Access Newsletter, Peter Suber posed the question back in 2006 as to whether a publisher would promise to reduce the subscription price in proportion to author uptake of the HOA option: 'If not, then it's simply introducing a way to be paid twice for the same articles. Neither authors nor subscribers should tolerate this; at least one of those parties is entitled to some relief' [7]. This accusation of 'double dipping' is the main point of criticism regarding HOA, and will be discussed in more detail in the next section.

- The stance of research organizations and research funding bodies on HOA varies. While, as already mentioned, HOA has been extensively supported in the UK since 2013, there is a fairly clear rejection in Germany. The Helmholtz Association, which is the largest research organization in the country, advises

\footnotetext{
${ }^{5} \mathrm{http} / / /$ comms.informahealthcare.com/what-we-do/publicationsupport/access/ (accessed 17 January 2015).

${ }^{6}$ E.g. http://informahealthcare.com/action/doSearch?field1=Contrib\& text1=Elder\& \& publication=jas results in just one hit (http://informahealthcare.com/doi/pdf/10.3109/ 02770903.2013.846369; accessed 17 January 2015), which has an 'open access' icon. This disclaimer as a watermark is obviously completely absurd because without authorization from the publisher, nobody is actually allowed to access the article who is not authorized to do so by a subscription to the journal.
}

against publication in HOA journals in its open access policy. ${ }^{7}$ In their framework agreements with OA publishers, which stipulate the advance payment of open access fees, both the Max Planck Society and the Helmholtz Association exclude the financing of HOA. ${ }^{8}$ The German Research Foundation (DFG) excludes HOA in its open access publishing programme': granting open access to individual papers in journals that are mainly subscription-based in line with the 'open choice' model is a mechanism that is not subsidizable. The Norwegian Research Councils takes a stand against HOA as well. ${ }^{10}$ Science Europe, which is an association of more than 50 European research organizations and research funding bodies, emphasizes:

The hybrid model, as currently defined and implemented by publishers, is not a working and viable pathway to Open Access. Any model for transition to Open Access supported by Science Europe Member Organisations must prevent 'double dipping' and increase cost transparency. ${ }^{11}$

\section{DOUBLE DIPPING}

The term 'double dipping' is used to describe a situation where publishers collect money twice: once when subscriptions are paid by the universities and research organizations and once when authors are additionally charged open access fees. ${ }^{12}$ Publishers vehemently deny that double dipping occurs or that this is their intention: 'If we assume from the beginning that hybrid open access should generally not be supported because publishers pocket fees twice, this doesn't exactly build confidence. It should go without saying that the licensing costs will be adjusted as necessary. ${ }^{, 13}$ In this regard, there are fundamental concerns that the lack of transparency associated with subscription fees will make it impossible to

\footnotetext{
${ }^{7}$ http://www.earlham.edu/ peters/fos/newsletter/09-02-06. htm (accessed 17 January 2015).

${ }^{8} \mathrm{http}: / /$ www.helmholtz.de/fileadmin/user_upload/01_fors chung/2013-10-14_OA-Richtlinie-IVF.pdf (accessed 17 January 2015).

${ }^{9} \mathrm{http}: / /$ www.wileyopenaccess.com/details/content/12f25 e2eb76/Institutional-and-Funder-Accounts-and-Discounts. html (accessed 17 January 2015).

${ }^{10}$ http://www.dfg.de/en/research_funding/programmes/infra structure/lis/funding_opportunities/open_access_publishing/ index.html (accessed 17 January 2015).

${ }^{11}$ http://www.digital-science.com/blog/guest/going-for-truegold-why-the-norwegian-research-council-is-taking-a-standagainst-hybrid-oa-journals/ (accessed 9 March 2015).

${ }^{12}$ http://www.scienceeurope.org/uploads/PublicDocuments AndSpeeches/SE_OA_Pos_Statement.pdf (accessed 17 January 2015).

${ }^{13}$ http://sparceurope.org/hybrid-journals/ (accessed 17 January 2015).
} 
Table 1. Publishers evaluated and their status with respect to hybrid open access according to details provided on their websites.

\begin{tabular}{|c|c|c|}
\hline Publisher & Country & Status hybrid OA \\
\hline American Chemical Society & USA & Hybrid OA \\
\hline BMJ & UK & Hybrid OA \\
\hline EDP Sciences & FR & Hybrid OA \\
\hline Emerald & UK & Hybrid OA \\
\hline Georg Thieme Verlag & DE & Hybrid OA \\
\hline Hogrefe \& Huber & $\mathrm{DE}$ & Hybrid OA \\
\hline IEEE & USA & Hybrid OA \\
\hline Informa Healthcare & UK & Hybrid OA \\
\hline Lippincott Williams \& Wilkins & USA & Hybrid OA \\
\hline Sage & UK & Hybrid OA \\
\hline Karger & $\mathrm{CH}$ & Hybrid OA \\
\hline American Physical Society & USA & $\begin{array}{l}\text { No double-dipping } \\
\text { policy }\end{array}$ \\
\hline Cambridge University Press & UK & $\begin{array}{l}\text { No double-dipping } \\
\text { policy }\end{array}$ \\
\hline De Gruyter & DE & $\begin{array}{l}\text { No double-dipping } \\
\text { policy }\end{array}$ \\
\hline Elsevier & $\mathrm{NL}$ & $\begin{array}{l}\text { No double-dipping } \\
\text { policy }\end{array}$ \\
\hline IOP Publishing & UK & $\begin{array}{l}\text { No double-dipping } \\
\text { policy }\end{array}$ \\
\hline Nature Publishing Group & UK & $\begin{array}{l}\text { No double-dipping } \\
\text { policy }\end{array}$ \\
\hline Oxford University Press & UK & $\begin{array}{l}\text { No double-dipping } \\
\text { policy }\end{array}$ \\
\hline Royal Society & UK & $\begin{array}{l}\text { No double-dipping } \\
\text { policy }\end{array}$ \\
\hline Royal Society of Chemistry & UK & $\begin{array}{l}\text { No double-dipping } \\
\text { policy }\end{array}$ \\
\hline $\begin{array}{l}\text { SPIE International Society of Optical } \\
\text { Engineers }\end{array}$ & USA & $\begin{array}{l}\text { No double-dipping } \\
\text { policy }\end{array}$ \\
\hline Springer & DE & $\begin{array}{l}\text { No double-dipping } \\
\text { policy }\end{array}$ \\
\hline Taylor \& Francis & UK & $\begin{array}{l}\text { No double-dipping } \\
\text { policy }\end{array}$ \\
\hline Wiley & USA & $\begin{array}{l}\text { No double-dipping } \\
\text { policy }\end{array}$ \\
\hline
\end{tabular}

Karger agreed after email contact to take article processing charges (APCs) into account in their pricing structure.

check any subscription discounts. Mike Taylor made this very explicit in an interview with Richard Poynder:

While most publishers offering hybrid promise a "no double dipping' policy, it's plainly impossible for anyone to verify whether this is true - and probably impossible for the publishers themselves to know. When the subscription costs paid by any given library are closely guarded secrets, and when in any case virtually every journal subscription is part of a Big Deal, is it even meaningful to talk about how much the price of any given journal is reduced to account for APCs paid? I don't think so. The only way to move forward with hybrid is by taking the legacy publishers' word on the financials. And no-one with half a brain or a few months' memory is going to do that, when they have shown over and over again that they're not trustworthy. ${ }^{14}$

Furthermore, there is the question of whether a global reduction in subscription fees is even the right way to go, or whether it would not make more sense for those institutions that financed the HOA articles to receive a reduction in subscription fees. This is the position taken by the Research Libraries UK for example:

Double-dipping adjustments or rebates from publishers should take effect at the level of individual institution. (...) A system which depends upon publishers passing on APC contributions to all subscribers will (i) be unverifiable from the point of view of the universities and other bodies making APC payments; and (ii) would so dilute the financial benefit to high APC-payers that its effects would be negligible. We believe (...) that the level of double-dipping adjustment or rebate a university receives from a publisher should be proportionate to its level of Gold open access publication with that publisher [8].

The question of whether double dipping occurs remains a subject of contention between publishers, on the one hand, and libraries, research organizations and research funding bodies, on the other hand. ${ }^{15} \mathrm{~A}$ final example of this is a post in Wiley's 'Exchange' blog by Bob Campbell entitled 'Open Access in the UK - will Gold or Green prevail?'

In terms of double dipping - the concern that publishers are collecting subscriptions and APCs for the same content - there is now some acceptance that this is not happening on a global scale, i.e. the APC revenue is taken into account when determining the subscription price.

Charles Oppenheim commented as follows on this: 'I'd like to see the evidence for that claim, and in particular whether that alleged acceptance is by libraries'. One year after posting the comment, there had still been no reaction. ${ }^{16}$ This contrasting assessment of the situation prompted a survey of publishers using concrete examples to establish whether double dipping is actually practised or not.

\footnotetext{
${ }^{14}$ http://poynder.blogspot.fi/2013/07/open-access-where-arewe-what-still.html (accessed 17 January 2015).

${ }^{15}$ House of Commons, Business, Innovation and Skills Committee, Open Access Fifth Report of Session 2013-14 Volume I: Report, together with formal minutes, oral and written evidence, 2013, London, House of Commons.

${ }^{16}$ http://exchanges.wiley.com/blog/2013/10/07/open-accessin-the-uk-will-gold-or-green-prevail/ (accessed 17 January 2015).
} 
Table 2. Figures for the Wiley journal Molecular Microbiology for 2011-2013 in normal font; list prices in italics are those for Europe for 2013-2015.

\begin{tabular}{|c|c|c|c|c|c|}
\hline & 2011 (2013) & $2012(2014)$ & $2013(2015)$ & $2011 \rightarrow 2012(2013 \rightarrow 2014)$ & $2012 \rightarrow 2013(2014 \rightarrow 2015)$ \\
\hline Number of articles & 446 & 338 & 306 & $-24.2 \%$ & $-9.5 \%$ \\
\hline Number of HOA articles & 29 & 32 & 50 & $+10.3 \%$ & $+56.3 \%$ \\
\hline Share of HOA & $6.5 \%$ & $9.5 \%$ & $13.5 \%$ & & \\
\hline Online open adjustment & & $-4.44 \%$ & $-3.20 \%$ & & \\
\hline List price Europe & $€ 5,280$ & $€ 5,374$ & $€ 5,515$ & $+1.78 \%$ & $+2.62 \%$ \\
\hline
\end{tabular}

The bold values came from Wiley, http://media.wiley.com/assets/7262/64/Onlineopenadjustments.xlsx and http://wileyonlinelibrary.com/ journals-prices (accessed 17 January 2015). The relevant lists for previous years are no longer available online but the author has a copy; the other were calculated by the author.

\section{DESIGN OF THE SURVEY}

Twenty-four publishers ${ }^{17}$ (see Table 1) were selected for the evaluation. They were selected on the basis of the number of articles from each publisher in the Web of Science. Imprints, subsidiaries, etc. were taken into account within the relevant parent company. Publishers were initially grouped into two categories based on the information available on their websites.

(1) The publisher offers HOA but lacks an explicit 'no double-dipping' policy ('hybrid OA').

(2) The publisher offers HOA and has an explicit 'no double-dipping' policy ('no double-dipping policy').

Depending on the classification, the publishers received one of the two emails:

(1) Please confirm that you lack an explicit no doubledipping policy.

(2) Please complete the questionnaire.

The English version of the two emails and the questionnaire are included in the Appendix.

The questionnaire aimed to ascertain exactly how a no double-dipping policy is manifested - in other words, the extent to which publishers return income from HOA fees by reducing licensing fees. Concrete figures were ascertained using a fictitious example which compared the price development with the price development of a journal with no HOA articles. Drawing on experience, variations of the question were also used to inquire whether only list prices or also individually agreed subscription fees are adapted and to ask what impact a general increase or decrease in the number of articles has. Attitudes towards alternative methods of refunding were also evaluated, such as directly refunding the institution that paid the HOA fee or the Royal Society of Chemistry's 'Gold for Gold' system.

${ }^{17}$ The survey additionally included publishers with no apparent HOA option as well as a number of German-language publishing houses. However, the present study will focus only on the internationally important publishers with a HOA option.
The emails were sent in December 2013. If no reply was received, at least one reminder was sent; publishers with a no double-dipping policy were re-contacted several times. Eventually, information had been collected on all publishers with a no double-dipping policy, albeit not always in the form of a completed questionnaire. The spokesperson for Karger pointed out that APCs are taken into account when setting the licensing fees but that this information had not yet been publicized on the website. On this basis, a questionnaire was subsequently sent to Karger.

\section{RESULTS}

(a) Publishers with HOA but lack of a no double-dipping policy The reactions of the publishers can be split into five groups:

(a1) No reaction upon request (American Chemical Society) or a provisional reply that ultimately did not provide any substantial information (BMJ, Emerald, Informa Healthcare, Sage).

(a2) A no double-dipping policy has not yet been implement, but it is planned for the near future (Lippincott Williams \& Wilkins).

(a3) Publisher does not want to double dip, but there have been too few cases of paid hybrid articles to implement a formal system (EDP Sciences, Georg Thieme Verlag, Hogrefe \& Huber). EDP Sciences also stated that it has a very liberal publishing policy overall, which includes free access to archived years.

(a4) Publisher claims that it does not double dip; however, the journal prices are influenced by considerably more factors than those included in the questionnaire which is why the questionnaire could lead to incorrect conclusions (Karger).

(a5) Publisher states that in a transition period, concerns regarding double dipping are appeased by offering additional discounts on APCs for HOA and gold open access if an institution has a deposit account for open access fees and if the same institution has also subscribed to a large number of the respective publisher's journals (IEEE).

(b) Publishers with HOA and a no double-dipping policy Publishers with a no double-dipping policy were willing to provide varying degrees of information; in no case was information completely withheld. In some cases, feedback 
was given in a short telephone conversation or email (American Physical Society, Cambridge University Press, Hogrefe \& Huber, SPIE); in some cases, detailed discussions were conducted with spokespersons for publishers (De Gruyter, Royal Society of Chemistry, Springer); and seven publishers at least partially completed the questionnaire (Elsevier, IOP Publishing, Nature Publishing Group, Oxford University Press, Royal Society, Taylor \& Francis, Wiley). The no double-dipping policies actually identified could then in turn be divided into several groups:

(b1) Two of the publishers contacted stated that they wanted to avoid double dipping, but that there had been too few real cases in the past to actually implement any refund mechanism. This group is therefore similar to a2/a3. On its website, De Gruyter says the following:

Therefore, De Gruyter guarantees that subscription prices in the case of journals and book prices will be lowered according to the share of open access income compared to the original calculation of the title. If the publisher's calculation for a specific book was for example a sales line of 10,000 Euro and a minimum of $20 \%$ of the income is generated through open access fees, the price of the book will be lowered by $20 \%{ }^{18}$

However, Sven Fund, CEO of De Gruyter, explained using financial figures that the income generated via HOA to date had not even come close to achieving such shares. ${ }^{19}$ Even though there was a general willingness to adjust subscription prices accordingly, he believed that there had been no need to actually do so yet. Cambridge University Press indicated that it would like to take open access into account in APCs in 2015:

Uptake of the open access option will be monitored and subscription prices modified to take this into account. Until recently, the uptake was too low to have any effect on subscription prices. The number of Open Access articles is only one factor used in the calculations involved in setting subscription prices, but this will be considered when we review the prices for $2015 .^{20}$

(b2) Two publishers stated that income from HOA fees is taken into account when setting prices. They did not make any precise information public (e.g. in press releases or in price lists) nor were they in a position to complete the questionnaire. The American Physical

\footnotetext{
${ }^{18} \mathrm{http}: / /$ www.degruyter.com/dg/page/560/de-gruyter-openlibrary (accessed 17 January 2015).

${ }^{19}$ Sven Fund, CEO De Gruyter, personal communication on 19 May 2014 and 26 May 2014.

${ }^{20}$ Aimee Connolly, CUP Customer Services Journals, email to the author dated 11 March 2014.
}

Society described its price calculation as follows ${ }^{21}$ : First the budget required is calculated, which also includes anticipated variables such as the number of articles to be published in future. Working backwards from this, the journal price is determined by estimating the number of subscriptions and a small cross-financing portion for APS. Based on the last five years' experience and a projection into the future, income from HOA fees is also estimated and taken into account.

In its comment, the International Society of Optical Engineers SPIE stated that journal prices had increased only moderately in the past, and in both 2013 and 2014, they had not increased at all. The representative emphasized that free access to the journal archive was available to all subscribers, and concluded with the following comment: 'I should add that our OA fee is actually less than the actual cost we incur to publish an article. It is the combination of $\mathrm{OA}$ fees and modest subscription revenue that enables SPIE to have low OA article charges. ${ }^{22}$

(b3) Springer takes HOA fees into account when setting journal prices and also documents this in detail. ${ }^{23}$ In this respect, Springer goes far beyond the vague statements made by publishers in group (b2). However, the exact procedure is not detailed. It is clear, in any case, that Open Choice articles, which were published within the scope of special agreements with certain universities and research institutions ${ }^{24}$ without additional fees being charged, are not accounted for in the calculation. However, the articles from these pilot programmes, all of which ended in 2012 at the latest [9], should no longer play a role. Furthermore, a threshold is employed below which journal prices are not reduced. The exact value of this threshold is not known, but it is probably no higher than $10 \%$. Although Springer authorized its spokesperson to speak to the author at length, ${ }^{25}$ it did not wish to complete the questionnaire.

(b4) The Royal Society of Chemistry takes an unusual approach. Within its 'Gold for Gold' programme, ${ }^{26}$ it issues the institutions that subscribe to the entire RSC

${ }^{21}$ Joseph W. Serene, APS Treasurer/Publisher, email to the author dated 16 January 2014.

${ }^{22}$ Eric Pepper, SPIE Director of Publications, email to the author dated 22 January 2014.

${ }^{23}$ http://www.springer.com/gp/open-access/open-access-trackrecord (accessed 17 January 2015).http://static.springer.com/ sgw/documents/1345327/application/pdf/Springer+Open +Choice_Journal+Price+Adjustments+2013.pdf

${ }^{24}$ http://osc.universityofcalifornia.edu/2009/01/cdl-and-sprin ger-sign-springer-open-choice-agreement/ (accessed 17 January 2015).

${ }^{25}$ Juliane Ritt, Executive Vice President Open Access \& Marketing Services, personal communication on 27 January 2014.

${ }^{26}$ http://www.rsc.org/Publishing/librarians/GoldforGold.asp (accessed 17 January 2015). 
journal programme, including its book series, with vouchers for HOA publications to the same amount. The approach pursued within the no double-dipping paradigm, whereby publication fees are deducted from subscription fees is turned on its head here. For institutions that have not subscribed to 'RSC Gold', the Royal Society of Chemistry is a publisher that falls into group (b2): when future subscription fees are set, income from OA publication fees is taken into account; however, no concrete information is provided.

Will RSC take author-pays revenues into account in setting future journal prices? Yes, but with the caveat that, along with many other publishers, RSC considers the author-pays open access model to be an experiment rather than a proven business model. Running this model alongside the normal subscription route for access represents a risk, and the RSC reserves the right to withdraw the authorpays open access model at any stage. ${ }^{27}$

The reference to the future in the question actually leaves it open as to whether not only an approach that is planned for the future is described here. This would place RSC in group (b1).

(b5) Six publishers (Elsevier, Nature Publishing Group, Oxford University Press, Royal Society, Taylor \& Francis, Wiley) at least partially completed the questionnaire ${ }^{28}$; in the case of another publisher (IOP Publishing), the author was able to complete at least one question on the basis of information provided in an email.

The initial situation was that a publisher publishes two journals - Journal A and Journal B - in the same subject area with the same number of subscribers. Both journals have a list price of $€ 1,000$ and contain 100 articles per annum. Journal A only contains 'normal' articles (toll access, referred to in the following as TA). Journal B contains 95 TA articles and $5 \mathrm{HOA}$ articles. It is assumed that in the following year, the price of Journal A is increased by $4 \%$ to $€ 1,040$. Question 1 was how high the price of Journal B would be in this constellation. If a publisher did not double dip and if it therefore reduced its journal price in proportion to the share of HOA articles, ${ }^{29}$ then the price of Journal B should be $€ 1,040$

${ }^{27}$ http://www.rsc.org/Publishing/Journals/OpenScience/FAQ. asp (accessed 17 January 2015).

${ }^{28}$ In this study, six scenarios are considered. The questionnaire covered eight scenarios in total and three additional questions.

${ }^{29}$ With the exception of RSC's Gold for Gold programme, all publishers exclusively pursue the concept of reducing journal prices to avoid double dipping (if they do anything at all). For this reason, only this approach is considered in the following. minus $5 \%$ as a discount $=€ 988$. This price was only given by Elsevier and IOP.

In its comment, IOP went on to discuss the questionnaire in detail and the various questions posed within it. The tenor is that the questions were oversimplified, but that in any case IOP is sincere in its efforts to avoid double dipping. Pilot projects have since been launched with FWF (Austria), where there is an offsetting of the HOA income against the subscription fees, ${ }^{30}$ and with JISC (United Kingdom) where $90 \%$ of the HOA income is refunded to the institutions and $10 \%$ is incorporated in the form of reductions in the global licensing fees [10]. This interesting approach should certainly be continued; for this study, however, the results were unavailable. The subsequent questions were not answered by IOP.

OUP took $80 \%$ of HOA income into account, which is why the price was only cut by $4 \%$ to $€ 998$. This damping is intended to prevent dramatic price fluctuations. ${ }^{31}$ This would be only understandable if a damping factor was used to achieve a balance between different journals or over a period of several years. However, this was not mentioned in the comment from OUP.

At Taylor \& Francis, Journal B would cost $€ 1,030$. No reason was given why the list price was only reduced by $€ 10(0.96 \%)$.

The Royal Society would charge $€ 1,040$ for Journal B, which would be exactly the same price as for a journal with no HOA articles. This was justified by assuming that the $4 \%$ price increase in this hypothetical situation represented the inflation rate, which would then apply equally to both Journal A and Journal B. In correspondence with the author, ${ }^{32}$ this was not expanded upon, but relevant information was found on the Society's website: ${ }^{33}$ according to the website, the prices for 2015 are set by comparing the publication years 2010-2012 with those of 2011-2013. The percentage change in the number of non-OA articles is added to the inflation rate [the current UK Retail Price Index (RPI) of $2.5 \%$ is used], and the resulting sum gives the individual price increase for each journal. If the number of HOA articles decreases, this figure can also be negative. To avoid strong price fluctuations, a cap is set at $20 \%$. For 2015 , the additional element was positive in four cases and negative in four cases. In two of these cases, the RPI value was even exceeded and thus

\footnotetext{
${ }^{30}$ Falk Reckling, Head of Department Strategy Analysis des Austrian Science Fund (FWF), email to the author dated 2 April 2015.

${ }^{31}$ Rhodri Jackson, Senior Publisher Oxford University Press, email to the author dated 19 February 2014.

${ }^{32}$ Marianne Haska, Institutional Open Access Consultant Royal Society, email to the author dated 9 January 2014.

${ }^{33}$ http://royalsocietypublishing.org/librarians/transparentpricing (accessed 17 January 2015).
} 
resulted in a price decrease. In one case, the $20 \%$ cap was actually enforced.

Both the Nature Publishing Group ${ }^{34}$ and Wiley $^{35}$ would also charge $€ 1,040$ for the HOA journal. The two publishers explained that the price would remain unchanged because the number of subscription articles had not changed. This reasoning indicates that neither publisher considers the share of HOA articles but rather the absolute number of TA articles. As a variation of the initial situation, it was assumed in scenario 2 that a library had licensed the journal at a lower price than the list price (namely €900) and that the library had also agreed a price increase of only $3 \%$. This scenario reflects the situation of subscriptions over several years with a price cap. It also accounts for the fact that a publisher can only change the list price but not prices that have been individually agreed upon. This approach is practised by Springer-Verlag.

If the HOA share of articles is taken into account fully, then the price of Journal B should be 5\% lower than the price of Journal A and cost $€ 880.65$. This was the price quoted by Elsevier.

OUP again only takes $80 \%$ of the HOA income into account and reduces the price of Journal B to $€ 889.92$.

Taylor \& Francis would charge $€ 918$ for Journal B. Again, there were no reasons given why only a $€ 9$ discount would apply $(0.97 \%)$.

With the same comments as before, the Nature Publishing Group, the Royal Society, and Wiley quoted a price of $€ 927$ for Journal B.

In scenario 3, it was assumed that both journals contained 110 articles last year, and 120 articles the year before that. Respondents were asked what would happen to the prices of Journal A and Journal B if the price of a journal that consistently had 100 TA articles increased by 4\%. Analogously, in scenario 4, it was assumed that both journals contained 90 articles last year, and 80 articles the year before that. These scenarios aimed to account for situations where a publisher could tie compensation for HOA fees to the evolution of the number of articles. This is practised by Wiley.

The publishers' answers indicate that the scenarios are apparently not very realistic. Elsevier explained that it understood scenario 3 as describing a journal with a continuous decline. In such an instance, the publisher would consider converting the journal completely into an open access journal. Aside from this, Journal B would again cost 5\% less than Journal A. Scenario 4 was understood as describing a situation that mainly applies to new journals. However, that no price differentiation had been

\footnotetext{
${ }^{34}$ Mona Singh, Institutional Sales Executive Nature Publishing Group, email to the author dated 23 October 2014.

${ }^{35}$ Paul Kwiatkowskyj, Regional Sales Director Wiley-VCH, email to the author dated 7 February 2014. Furthermore, Wiley states that other factors could also influence the price structure such as changes in the impact factor or changes in the number of other articles such as research and review articles.
}

implemented between the journals in previous years was extremely improbable according to Elsevier.

The Nature Publishing Group would mostly implement the regular price increase in both scenarios because a more extensive price adjustment would only be implemented if the number of TA articles grew by more than $10 \%$. This was the case for Journal B in scenario 4 where the number of TA articles grew by more than $11 \%$. As a result, a discretionary decision could be taken to increase the price of Journal B by $15 \%$ in total to $€ 1,150$.

OUP assumed that no price differentiation would occur for Journal A in either scenario. However, since no concrete figures were provided on the number of HOA articles, it could not make any concrete statement regarding Journal B.

Taylor \& Francis stated that the price should be adjusted not in relation to the number of articles but rather in relation to the number of pages. In scenario 3, the price of Journal A would be reduced by a set (undisclosed) percentage of the decrease in articles and then increased by $4 \%$ (inflation rate). The same would apply to Journal B, although an additional adjustment would be made here due to the HOA articles (extent undisclosed). A similar procedure would apply in scenario 4; no concrete figures were given here either.

The Royal Society did not consider itself in a position to quote any prices because the number of TA articles in the past four years were not given and it referred once again to its Transparent Pricing Mechanism. ${ }^{36}$

For scenario 4, Wiley would not increase the price beyond the normal price increase of $4 \%$. It would also apply the normal price increase of $4 \%$ in scenario 3 unless fewer TA articles had been published in the journal with an increasing number of HOA articles.

Scenarios 5 and 6 were intended to identify what sort of scale the publishers used. Would the same apply if instead of five HOA articles only one (and 99 TA articles) were published (scenario 5)? Or do publishers have a threshold beyond a share of $5 \%$ HOA that must be reached before any discounts are even given, e.g. a share of $10 \%$ (10 HOA articles, $90 \mathrm{TA}$ articles; scenario 6)?

No scaling effects were apparent for Elsevier; Journal B was either $1 \%$ or $10 \%$ cheaper than Journal A. It cost $€ 1,029.60$ in scenario 5 and $€ 936.00$ in scenario 6 .

The Nature Publishing Group did not decrease the prices in any scenario because the threshold of a $10 \%$ change in the number of TA articles had not been reached.

OUP again only took $80 \%$ of the HOA share into account, but in scenario 5 , it would still give a discount of $1 \%$ (instead of $0.8 \%$ ). The price of Journal B would then decrease to $€ 1,029.60$. In scenario 6 , the price of Journal B would drop by $8 \%$ to $€ 956.80$.

\footnotetext{
${ }^{36}$ http://royalsocietypublishing.org/librarians/transparentpricing (accessed 17 January 2015).
} 
For scenario 5, Taylor \& Francis quoted a price of $€ 1,040$ for Journal B because the HOA share did not exceed the threshold for an adjustment. How exactly the threshold is defined was not explained. In scenario 6, the price of Journal B would be $€ 980$. This corresponds to a reduction of $9.77 \%$. Again, there was no explanation given as to how this price reduction was calculated. Wiley would not reduce the price in any scenario unless there had been more than 99 or 90 TA articles, respectively, the year before. This once again highlights the special aspect of Wiley's price policy: prices will only be reduced if the number of TA articles decreases 'due to' HOA articles.

\section{DISCUSSION}

About 5 of the 24 publishers in this study either did not reply or provided trivial information (American Chemical Society, BMJ, Carl Hanser Verlag, Emerald, Informa Healthcare, Sage, Schluetersche Verlagsgesellschaft). This is questionable business conduct; however, at least none of these publishers claims to have a no double-dipping policy. We can therefore take the perspective that the publishers listed are aware that they double dip, but that they prefer not to talk about it.

Although most of the publishers did not complete the questionnaire, the replies they did provide were not totally insubstantial.

- Often the publishers stated that although they did not wish to double dip as a principle, the number of cases was still too low to establish a formal system (Cambridge University Press, EDP Sciences, Georg Thieme Verlag, Hogrefe \& Huber, Lippincott Williams \& Wilkins, Oekom Verlag, Schattauer). With remarkable openness, De Gruyter actually provided the author with detailed figures on the generally very low number of HOA articles and the related proceeds. ${ }^{37}$ It stated that a formal system would be implemented in future if the number of cases increased. Cambridge University Press and Lippincott Williams \& Wilkins announced concrete plans for this in 2015. Overall, it is not difficult to understand the publishers' perspective that a refund system would not be worth it for such small numbers. However, a remaining point of criticism is that in principle double dipping begins with the very first article - to reverse the argument no publisher ${ }^{38}$ would dispense with the payment of HOA fees simply because only a few articles are involved.

- A second group of publishers claims not to double dip and to be unable to complete the questionnaire because their journal prices are set in a completely different manner than that assumed in the questions.

${ }^{37}$ Sven Fund, CEO De Gruyter, personal communication on 26 May 2014.

${ }^{38}$ An exception in this respect involves special measures such as editorial waivers or Springer's aforementioned Open Choice projects with different institutions. If no fees are charged in these cases, then naturally there is no double dipping.
This was communicated in very terse form (Karger), or sometimes with detailed explanations (APS, SPIE). In these cases, the practice of double dipping can be considered a priori to be neither confirmed nor rejected. Certainly, the appraisal depends on the extent to which the protestations can be believed. Empirically, this could be determined by comparing price increases and the share of HOA in different journals offered by the same publisher: if the publisher's information is correct, there should be a negative correlation. However, such an evaluation is beyond the scope of the present work.

- Some publishers also (additionally) referred to their low price increases (SPIE) or to other favourable conditions that they offer (EDP Sciences, IEEE). Such references indicate the limitations of the present study: it is limited to the evaluation of a no double-dipping policy and does not take a publisher's overall policy into account. In general, a rather negative appraisal of how a publisher deals with double dipping can be compensated, indeed overcompensated, by a publisher's otherwise very positive features (heavily used and highly cited articles, low journal prices, low price increases, liberal regulations on green open access, CC-BY licence for gold open access, etc.). Conversely, a positive appraisal of how double dipping is dealt with does not necessarily mean that the publisher is automatically one of the 'good guys' when it comes to other matters.

- Springer did not wish to complete the questionnaire, but a senior representative was available for a detailed discussion. From other contexts, it is known that Springer reduces subscription fees in proportion to the number of Open Choice articles. However, there is a threshold under which no adjustments are made. Furthermore, only list prices are reduced, which is why neither licensees with a price below the list price nor subscribers to the King Size collection ${ }^{39}$ benefit. Prices are therefore reduced based on the number of Open Choice articles, which are fortunately transparently documented (cf. reference 32), but these discounts do not apply to all licensees and the threshold renders them incomplete.

- With respect to those institutions that have licensed the full journal programme, the Royal Society of Chemistry does not double dip (or hardly does so). The reason for adding that it hardly does so is that, for example, there may be insufficient numbers of articles from each institution for which the vouchers issued within the Gold for Gold programme ${ }^{40}$ could be used. Transferability of the vouchers to other institutions and/or beyond the year of agreement would therefore be desirable. Indeed, with regard to institutions that

\footnotetext{
${ }^{39}$ Access to non-subscribed Springer journals at a freely negotiated flat rate.

${ }^{40}$ http://www.rsc.org/publishing/librarians/goldforgold.asp (accessed 17 January 2015).
} 
cannot or do not wish to license all journals, the vouchers should also be made available outside the Gold for Gold programme.

Seven publishers (Elsevier, IOP Publishing, Nature Publishing Group, OUP, Royal Society, Taylor \& Francis, Wiley) made concrete comments on the calculation examples in the questionnaire.

Elsevier explained all price adjustments plausibly; above all, the adjustments fully met expectations. According to this explanation, Elsevier reduces its subscription fees in proportion to the share of HOA articles. The same principle also applies to all derived scenarios. This extremely encouraging result unfortunately contradicts the experience of the author and the experience of other colleagues from Germany (negotiators of various consortia) as there is no known case where Elsevier actually acted on these words and adjusted prices based on the number of HOA articles.

In a subsequent detailed discussion with two senior representatives ${ }^{41}$ from Elsevier, there was clear agreement on the principle of no double-dipping and also a clear disagreement on the question of how prices are calculated and what is received for a license fee:

- Elsevier's position is that subscription prices depend (among other factors) on the number of subscription articles only. HOA articles come on top of this. If Elsevier reduces subscription prices, it is because of the declining number of subscription articles. This decline in subscription articles may be because there are more HOA articles in a journal or because there is less interest from researchers in publishing in that title and therefore fewer submissions.

- In contrast to this, the author considers the subscription price of a journal for any subscriber as payment for access to the whole journal (cover to cover). If some of the articles are HOA articles, then this represents additional income for the publisher which should be refunded.

- It is Elsevier's position that HOA article publishing is an additional revenue stream, sometimes but not always from the same source as subscription revenue, and for an entirely different tranche of articles which have not been charged for in any other way.

- The authors pointed out that the vast majority of subscription and article publishing revenue comes from the same sources, namely public funded research organizations, public funded academic organizations and research funders. Again, the HOA articles are not considered as being separate from subscription articles. They are paid by subscribers of electronic journals just like they are paid for by subscribers to print journals.

\footnotetext{
${ }^{41}$ Alicia Wise, Director of Access and Policy, and Leo de Vos, Head of Pricing, exchange of emails with the authors between August 2014 and January 2015
}

- The Elsevier representatives claimed that there had been 2014 price reductions in 26 cases.

- The author had not encountered any reductions due to HOA in any license agreements he is aware of. Elsevier have now published more information about these 26 titles: http://www.slideshare.net/aliciawise/ price-adjustment-slide-43429236. ${ }^{42}$

- Elsevier pointed out that many subscribers have package/consortial deals which include deep discounts from subscription list prices. These discounts are deeper than the reductions in the subscription prices of the 26 hybrid titles. These subscribers are not being disadvantaged.

- The author did not adopt the position that package/ consortial discounts can be mixed with refunding in the context of HOA.

- The Elsevier representatives pointed out that if the same HOA articles have been published in fully OA journals then APCs would be paid to cover their publication costs and there would be no wrongful accusation of double-dipping.

- The author agreed but pointed out that there are no subscription fees in the case of fully OA journals.

- Elsevier suggested to explore ways to more clearly delineate/separate the $\mathrm{OA}$ and subscription sections of hybrid journals which might be helpful also from the author's point of view.

IOP reduced the price of the journal with HOA articles by the expected value in the initial scenario. The remaining questions were not answered directly but IOP did comment in depth on various issues. IOP has initiated pilot projects with JISC (United Kingdom) and Austria (FAF) where (at least) $90 \%$ of the HOA income is refunded to the institutions.

The Nature Publishing Group did not reduce the price in any scenario because the number of TA articles is decisive and adjustments are only made if there is a change of more than $10 \%$ in these articles. This means that prices are only reduced when (1) the number of TA articles decreases 'due to' HOA articles and (2) the decrease exceeds a threshold of $10 \%$.

In general, OUP took $80 \%$ of the HOA share into account, reducing for example the price of a journal with a HOA share of $10 \%$ by $8 \%$. The reasoning that this damping will counteract possible strong fluctuations in prices is not very convincing.

Taylor \& Francis reduced the prices in almost all instances, but always only to a limited extent. Where a $1 \%$ reduction was expected, no reduction was given. When - as in most cases - a $5 \%$ reduction was expected, a reduction of around 1\% was given, and instead of a $10 \%$ reduction, a discount of $5.8 \%$ was

\footnotetext{
${ }^{42}$ The author's library has subscribed to two of these 26 journals. Journal of molecular biology had a price decrease of $-0.5 \%$ (not -8.2\%); Trends in biotechnology had a price increase of $12.4 \%$ (not $0 \%$ ). The license fee for the Freedom Collection was not influenced by these price adjustments.
} 
given. The publisher did not explain why it gave a smaller reduction than expected nor did it detail how precisely this reduction was calculated.

The Royal Society assumed consistently that the $4 \%$ price increase for the pure TA journal represented the inflation rate, which should also be applied to the journal with a certain share of HOA. For this reason, no price reductions would apply to this journal due to the assumption made by the publisher that the number of TA articles had remained constant over the last four years.

Wiley did not reduce the price in any of the scenarios presented (but it does in reality!). Prices are only reduced when the number of TA articles decreases 'due to' HOA articles. Wiley therefore pursues a different approach to that put forward by the author (and most of the protagonists). Usually, it is assumed that for the (prepaid) subscription fees, the subscribers receive a set number of issues of the journal with a roughly estimated number of articles. If authors decide to pay a HOA fee when they submit the article (or after it has been accepted), then this represents additional income for the publisher which was not calculated in advance. A constant total number of articles is therefore assumed, of which a number then become HOA articles. In contrast, Wiley assumes that the number of TA articles generally remains the same and that HOA articles would be on top of this. If the number of TA articles decreases, then a refund is given. In itself, this would be an acceptable approach but it must be consistently implemented. ${ }^{43}$ First, in adjusting prices, Wiley leaves the fixed costs unchanged. ${ }^{44}$ Second, no price adjustment is made if the HOA share is low or almost zero. ${ }^{45}$ Furthermore, some journals owned by scientific societies continue to be excluded from price adjustments. The number of these titles has even risen from five (prices for 2014) to nine (prices for 2015). ${ }^{46}$ Regardless of all of this, the price adjustment level is unsatisfactory. Figures are given as an example in Table 2 for the journal Molecular Microbiology for the reference years of 2011-2013 (prices: years 2013-2015).

If the actual price increase is considered in relation to the online open adjustment, then the two variables together give the standard price increase of $6 \%$ almost exactly $(4.44 \%+$

\footnotetext{
${ }^{43}$ From an ethical perspective, this position can still be opposed: if a journal has reached its calculated number of articles purely with TA articles, then every additional HOA article means additional revenue. This can easily influence the rejection rates of said HOA articles.

${ }^{44} \mathrm{http}: / /$ olabout.wiley.com/WileyCDA/Section/id-816521.html (accessed 17 January 2015).

${ }^{45}$ http://media.wiley.com/assets/7262/64/Onlineopenadjustments.xlsx (accessed 17 January 2015).

${ }^{46}$ http://media.wiley.com/assets/7262/64/Onlineopenadjustments.xlsx (accessed 17 January 2015). The document entitled 'Online Open Adjustments 2014' is no longer available online but the author has a copy.
}

$1.78 \%=6.22 \% ; 3.20 \%+2.62 \%=5.92 \%)$. However, the online open adjustment does not come close to reflecting the HOA share, which is two to four times larger. The total volume of the journal is not taken into account at all: from 2011 to 2013 , it decreased by $31 \%$ overall, while the list price increased by $4.5 \%$ despite online open adjustment.

Therefore, we can conclude that there is apparently no publisher who never double dips. The spectrum ranges from $100 \%$ double dipping to very general statements that cannot be verified on price setting and partial price reductions (i.e. double dipping $<100 \%$ ) right up to a case with supposed $0 \%$ double dipping that has yet to be confirmed in practice. The question remains as to whether HOA would also be possible without fees at a level that in some cases would exceed the publication fees in gold open access journals offered by the same publisher: is it conceivable that the publisher would only charge a fee to cover costs that would then not need to be refunded? Within the pay-per-view scheme, some publishers grant a specific IP address or an IP address range access to a certain article for 24 hours and subsequently deactivate access. For this access, a fee of $€ 10-€ 20$ is charged. The effort of granting permanent access to the article for all IP addresses (=gold open access) cannot be any greater. Consequently, only the transaction costs of approx. $€ 10-€ 20$ per article must be covered. From the publisher's point of view, however, this would lead to unwanted side-effects ${ }^{47}$ : For such low HOA fees, a large number of authors, or even all authors, would choose the HOA option. As a result (almost) all articles would be freely accessible. The danger cannot simply be dismissed that this would lead to massive subscription cancellations because access would of course be possible without subscriptions. The publisher would then have to convert the journal to gold open access. This would happen without the publisher being (anywhere near) sure that the authors would be willing to pay the necessary level of APCs (at least three-figure but mostly four-figure euro sums). This appears to be a risk that publishers are not ready to take. All in all, HOA therefore appears doomed to failure because publishers are not willing to offer it for fees that simply cover the costs and because at the fees currently charged the science community, research funding bodies, and the library sector are critical of double dipping. And as this study has shown, double dipping is indeed a reality.

\section{ACKNOWLEDGEMENT}

The author gratefully acknowledges the assistance of the Language Services of Forschungszentrum Jülich in preparing the manuscript.

\footnotetext{
${ }^{47}$ The author would like to thank Sven Fund, CEO of De Gruyter, for providing relevant information in a discussion on 4 June 2014.
} 


\section{REFERENCES}

[1] Björk BC. The hybrid model for open access publication of scholarly articles: A failed experiment? J Am Soc Inf Sci Technol. 2012;63(8):1496-1504. doi:10.1002/asi.22709.

[2] Morgan C, Bob C, Teleen T. The role of the academic journal publisher and open access publishing models. Int Stud Perspect. 2012;13(3):228-234. doi:10.1111/j.1528-3585.2012. 00495.x.

[3] Swan A. The Open Access citation advantage: Studies and results to date, 2010. University of Southampton. [cited 17 Jan 2015]. Available from: http://eprints.soton.ac.uk/id/eprint/268516.

[4] Mueller-Langer F, Watt R. The hybrid open access citation advantage: how many more cites is a $\$ 3,000$ fee buying you? 2014. Max Planck Institute for Innovation \& Competition Research Paper No. 14-02. [cited 17 Jan 2015]. Available from: http://papers.ssrn.com/sol3/papers.cfm?abstract_id=239 1692.

[5] Emery J. Mining for gold: identifying the librarians' toolkit for managing hybrid open access. Insights. 2013;26(2):115-119. doi:10.1629/2048-7754.65.

[6] Solomon DJ, Björk BC. A study of open access journals using article processing charges. J Am Soc Inf Sci Technol. 2012;63 (8):1485-1495. doi: http://dx.doi.org/10.1002/asi.22673.

[7] Hauff A. Wissenschaftliche Publikationen und „freier“ Zugang alternative Geschäftsmodelle oder Freibier für alle? Bibliothek, Forschung und Praxis. 2013;37(1):25-31. doi: http://dx.doi.org/ 10.1515/bfp-2013-0014.

[8] Research Libraries UK. Fair prices for article processing charges (APCS) in hybrid journals, 2013. [cited 17 Jan 2015]. Available from: http://www.rluk.ac.uk/wp-content/uploads/2014/02/ RLUK-stance-on-double-dipping-Final-November-2013.pdf.

[9] Schmidt B, Shearer K. Licensing revisited: open access clauses in practice. LIBER Q. 2012;22(3):176-189. URN:NBN:NL:UI:10-1113939.

[10] Harris S. OA interviews: Nicola Gulley, IOP Publishing. Res Inf. 2014;62 (August/September). [cited 17 Jan 2015]. Available from: http://www.researchinformation.info/features/feature.php? feature_id $=472$

\section{COMPETING INTERESTS}

The author declares no competing interests.

\section{PUBLISHING NOTES}

(C) 2015 B. Mittermaier. This work has been published open access under Creative Commons Attribution License CC BY 4.0, which permits unrestricted use, distribution, and reproduction in any medium, provided the original work is properly cited. Conditions, terms of use and publishing policy can be found at www.scienceopen.com.

Please note that this article may not have been peer reviewed yet and is under continuous post-publication peer review. For the current reviewing status please click here or scan the QR code on the right.

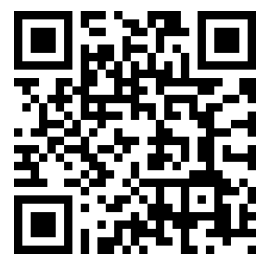

\section{ScienceOPEN.com

\section{APPENDIX}

\section{Email to publishers with hybrid option but lack of a 'no double-dipping' policy}

Dear XXX,

I am currently compiling an overview of publishers who offer hybrid open access. One of the aspects I am interested in is whether you have implemented a 'no double-dipping' policy. This means that the subscription price of the journals depends on how many hybrid open access articles have been published. Some publishers have implemented such a mechanism. However, I have been unable to find any indication on your website that you have done so. If this is not the case, please send me details of your policy.

Yours sincerely,

\section{Email to publishers with hybrid option and 'no double-} dipping' policy

Dear XXX,

Like other publishers, XXX has a 'no double-dipping' policy according to which hybrid open access articles do not have to be paid for twice (author charges + subscription fees). I have read the explanations under XXX but still have several questions. I would appreciate it if you could read through the attaches examples and use them to explain how your 'no double-dipping' policy is implemented in practice. Please fill in the pdf file and email it back to me.

I have sent similar letters to a number of other publishers. The answers I receive will serve as a basis for the decision on how Forschungszentrum Jülich and the Helmholtz Association will position themselves in future towards hybrid open access. I also plan to publish a paper detailing the results of my research in a library journal.

Thank you for taking the time to answer my questions. Please do not hesitate to contact me should you have any further questions.

Yours sincerely,

\section{Questionnaire $^{48}$}

Initial situation: Let us assume that you publish two journals: A and B. Furthermore, let us assume that both journals focus on the same subject area and have the same number of subscribers, and that both journals have a list price of $€ 1000$ and contain 100 articles per annum. Journal A only contains 'normal' articles (toll access, referred to in the following as TA). Journal B contains 95 TA articles and 5 hybrid open access articles (referred to as $\mathrm{OA}$ in the following).

(1) Case 1: Next year, you increase the price of Journal A by $4 \%$ to $€ 1040$. What would the price of Journal B be? (Should it be relevant in answering the question, please assume that Journal B still has $95 \mathrm{TA}$ articles and $5 \mathrm{OA}$ articles, as was the case in previous years.)

(2) Case 2: A library has licensed both journals, each for $€ 900$, and agrees to a price increase of $3 \%$ in the following year. It therefore pays $€ 927$ for Journal A. What would the licence fee for Journal B be?

(3) Case 3: Let us assume that both journals contained 110 articles last year, and 120 articles the year before that. What would happen to the prices of Journal A and Journal B if the

\footnotetext{
${ }^{48}$ The questionnaire covered two additional scenarios and three additional questions which are not considered in this publication.
} 


\section{SOR-SOCSCI B. Mittermaier: Double dipping in hybrid open access - chimera or reality?}

price of a journal that consistently has $100 \mathrm{TA}$ articles increases by $4 \%$ ?

(4) Case 4: Let us assume that both journals contained 90 articles last year, and 80 articles the year before that. What would happen to the prices of Journal A and Journal B if the price of a journal that consistently has $100 \mathrm{TA}$ articles increases by $4 \%$ ?

(5) Case 5: Journal B does not contain 5 OA articles but only 1 $\mathrm{OA}$ article and $99 \mathrm{TA}$ articles. All other factors are the same as in case 1 . What would the price of Journal B be?
(6) Case 6: Journal B does not contain $5 \mathrm{OA}$ articles but $10 \mathrm{OA}$ articles and 90 TA articles. All other factors are the same as in case 1 . What would the price of Journal B be?

(7) You take over Journals A and B as defined in case 1 from another publisher and set a price of $€ 1040$ for Journal A. What would the price of Journal B be?

(8) Conversely, what would happen to the open access fees already received if you were to sell the journal next year to another publisher? 